\title{
To walk on the Penrose stairs of science
}

\author{
Ho Manh Toan \\ Centre for Interdisciplinary Social Research, Phenikaa University, Hanoi, Vietnam \\ Nguyen To Hong Kong \\ Ritsumeikan Asia Pacific University, Beppu, Oita, Japan \\ Vuong Thu Trang \\ Sciences Po, Paris, France \\ Nguyen Minh Hoang \\ Ritsumeikan Asia Pacific University, Beppu, Oita, Japan \\ Ho Manh Tung \\ Ritsumeikan Asia Pacific University, Beppu, Oita, Japan
}

Published: 10 October 2019

Behavioural \& Social Sciences at Nature Research (https://socialsciences.nature.com/). Is it publish or perish?. URL: https://socialsciences.nature.com/channels/2140-is-it-publish-orperish/posts/54541-to-walk-on-the-penrose-stairs-of-science.

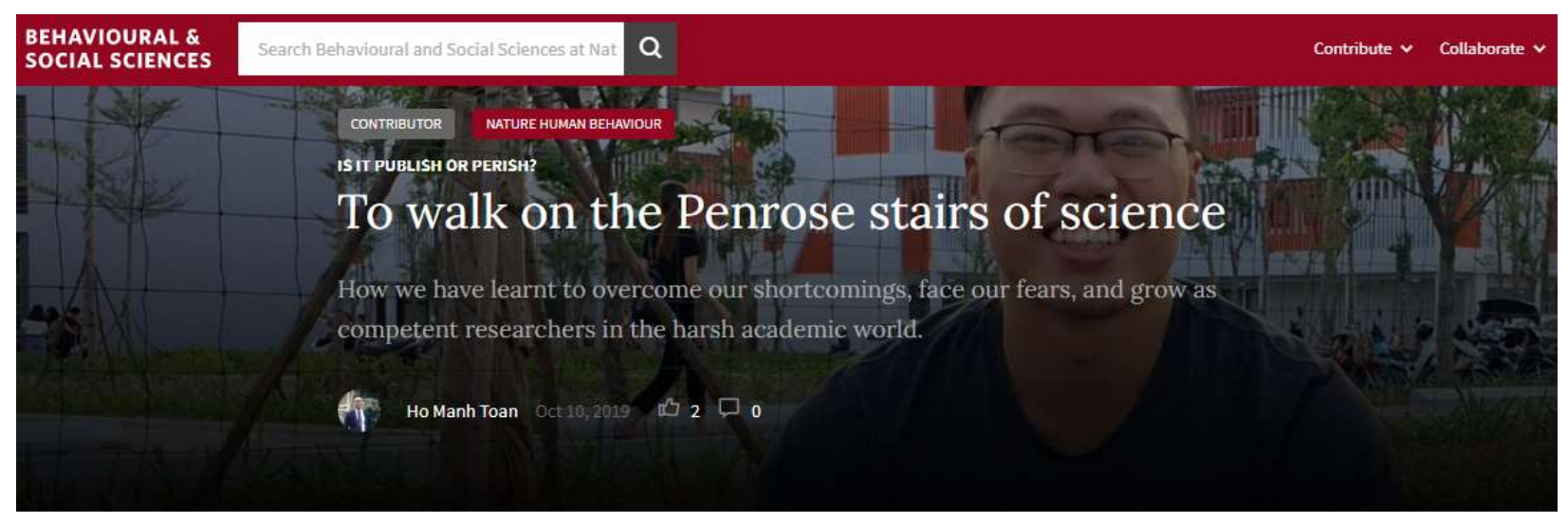


I first started this post with the idea of sharing my personal story: a young researcher who is based in Hanoi, Vietnam, and in two years, has earned a place as a co-author in 15 publications. I would never have been able to achieve this feat in such a short amount of time without my research team. Their ambition, determination, and sense of responsibility have driven our total count of published articles towards 53 thus far, with several manuscripts still in the pipeline:

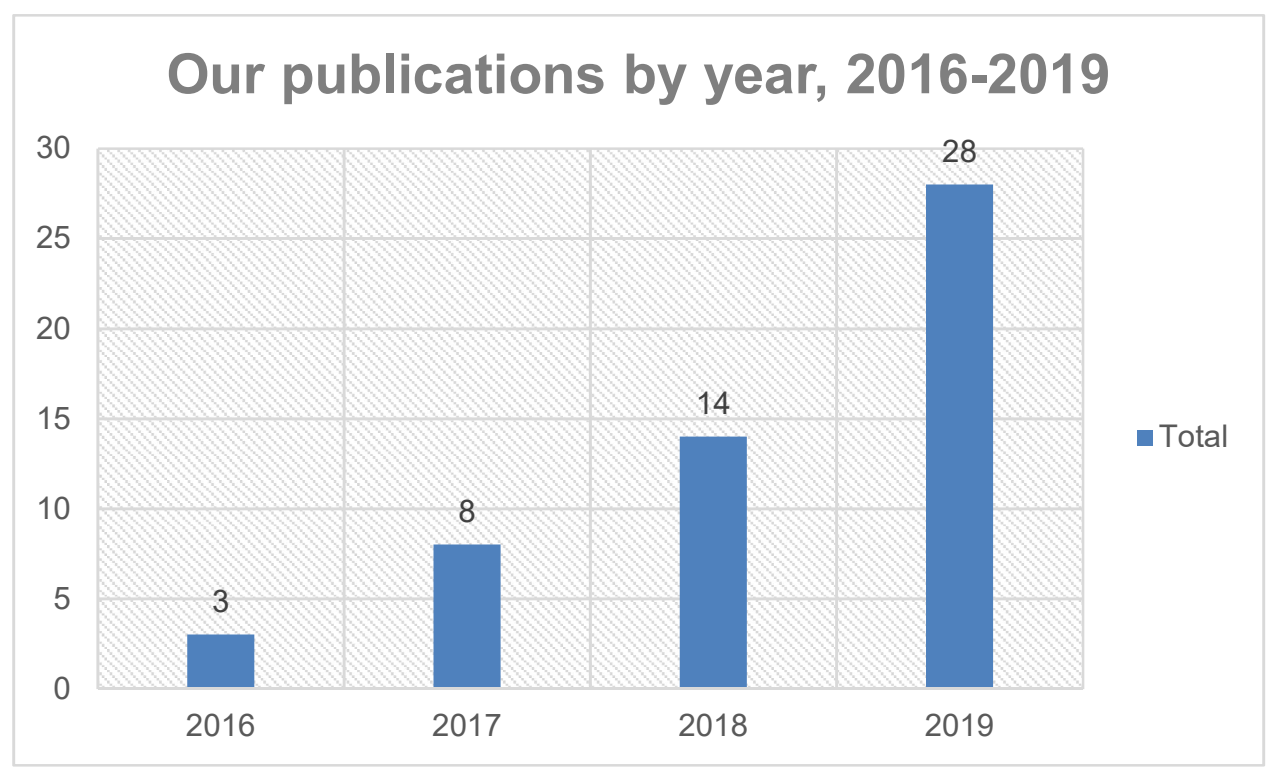

The number might seem like that of a lifetime's achievement, and yet we are all under 30 years old: the oldest is 29 (Ho Manh Tung and Nguyen To Hong Kong), and the youngest is only 22 (Vuong Thu Trang). All of us are pursuing master's degrees, and for now, only Nguyen Minh Hoang, has already decided on his next step as a Ph.D. candidate in Japan. So, let me tell you about how Trang started pursuing her ambitions when she was only 18; how Tung and Hong Kong take turns taking care of their daughter, Sophie, while the other person works on a manuscript; and how we have learnt to overcome our shortcomings, face our fears, and grow as competent researchers.

\section{The beginning}

My journey began after I finished my bachelor's degree in Japan and went back to Vietnam in 2017. My brother, Tung, who had been working as a researcher, asked me to help with collecting data for his research project. The project eventually resulted in several publications, including one in Scientific Data [1], and two websites: the SSHPA database (http://sshpa.com/) and EASE Vietnam SciComm System (https://sc.sshpa.com/). Next thing I knew, I have joined the lab and continued to work under the supervision of our mentor.

While Tung, Hong Kong, Hoang and I barely understood what it meant to be a scientist when we were teenagers, Trang had always wanted to be one since a very young age:

"When I was ten years old, my English teacher posed the classic question, "What do you want to do when you grow up?" I was lucky to be seated at the back of the room 
because the time it took for all my classmates to answer was barely enough for me to debate on my answer. I wanted to be an artist and a scientist, and I said so. 'At the same time, 'I remember adding, hesitantly. My teacher patiently confirmed my fear: They were, apparently, polar opposite occupations. He congratulated me for the interesting answer nonetheless.

"A decade later, I realized that perhaps artists and scientists were not so different after all. Art has its methodology, and science has its spontaneity. Romanticism aside, there is another parallel to be drawn between the artistic and the academic worlds: they are both fiercely competitive. With twenty-one springs under my belt, I am the cadet of my research team and perhaps one of the youngest in my field and my country. Academia has no mercy on the young - I say this from experience."

Meanwhile, Hong Kong had not embarked on a career in academic right out of college or even as part of graduate school. She shared:

"I was working as an editor for a private media monitoring company in Hanoi and taking maternity leave from said job. When my daughter was four months old, in-between my time of changing diapers, breastfeeding, and entertaining our newborn, I began to find myself assisting my husband in his research work. In our first joint research paper, we had read extensively about studies on sustainability and sustainable social sciences, from which we argued for the need for sustainable research networks [2]."

\section{Becoming researchers through publishing}

Doing research both requires and accumulates a collection of many skills, all of which must tune together in order for a researcher to produce works that not only contribute to the knowledge pool - the classic "quest for truth" of Science, with a capital S - but also respond to very practical needs of society. Even the most basic of skills - sorting physically filled survey forms, for example - could take a lot of time to master. That is why an average doctoral candidate needs at least four years to complete his or her dissertation. For this reason, young researchers are often better off being in a team with efficient division of labor. Such a setting would allow them to gradually master one skill at a time, while still being able to produce a finished product.

Our mentor encourages us to share the responsibilities of conducting research. For instance, besides rotating to take on the usual tasks of a research project, which range from data collection, analysis, to manuscript writing and revising, we each have different strengths that complement one another and overall supplement the final product. For instance, Trang and Hong Kong are the "editors" of our team, Hoang conducts data analysis, while Tung and I work on coordinating team members and ensuring the timely completion of a project. Despite the varying tasks, we share the same goal of protecting scientific integrity and sharing our works with the international scientific community. At our age, each published article bolsters our confidence and reaffirms our ability to contribute something to the world. 


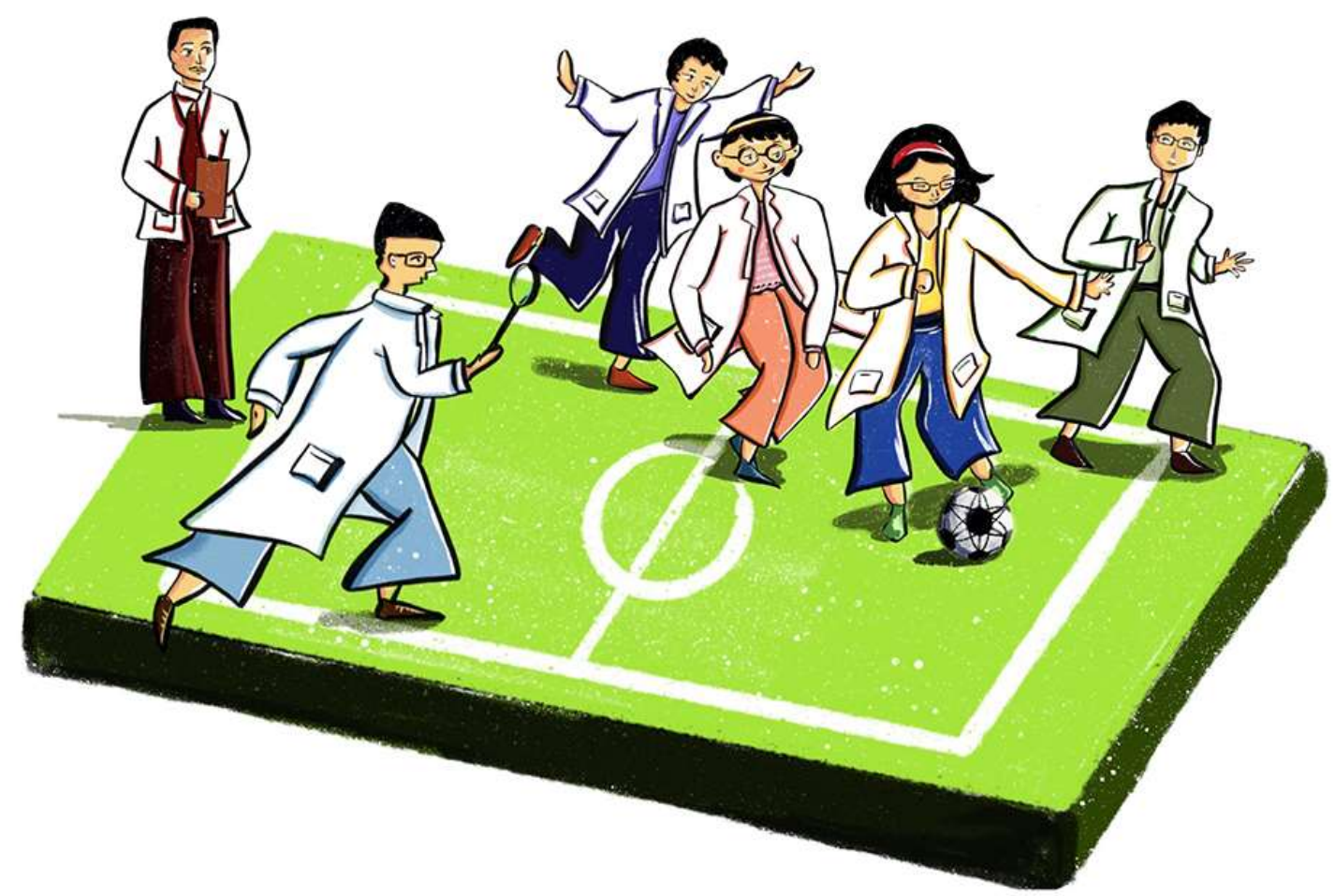

Gants

Research is a team sport. In football, you pass the ball, and then trust that your teammates will find you in a good position to score. In research, sharing the workload with your team members, and finishing your part efficiently will create a special connection between you and your teammates. (@ drawing courtesy of Anh Hoang Ho)

A great lesson of working under pressure to publish is how to deliver a finished product when the time comes. In the beginning, we all have the feeling that a manuscript must be perfect once we submit it. However, even for a manuscript that we thought was flawless, it could still go through several rounds of major revision. For instance, our article on Palgrave Communications [3] went through two rounds of peer review, with two reviewers that commented on our paper extensively (8 pages of comments and an additional PDF with point-by-point comments directly on the manuscript). The lesson is, even though the submitted manuscript might not be as good as we felt it should be, it is always better to submit than to leave it hanging to dry. And dealing with harsh reviews is much easier when you understand that your manuscript will always have room for improvement. The peer-review process, as disheartening and draining it may feel to some (many) researchers, is not meant to put you down; and even if your work doesn't go through, it does not invalidate your efforts.

\section{The anxiety}


"Are we merely drops in the ocean of knowledge?" "Can we make it to the end of the journey?" "Can I seek truth without trapping myself in an ivory tower?" "Do I deserve it?" "Am I worth it?"

These are the questions that we always ask ourselves for every publication with our names on, and for every step along the journey. Even in a well-organized team, the questions poke at us regularly. Indeed, academia can be overwhelming with its centuries of knowledge. We are easily flushed with uncertainty about whether our works can contribute something significant, or whether our abilities can match with others around the world.

Writing in English and using advanced statistics are among our first challenges. Translating ideas into written form is a tough process, even in our native language. Most of our drafts still require heavy editing because of grammatical and logical mistakes. But shying away from the task of writing would not fix the problem. It is only through practice - that is, writing, rewriting, and working on more manuscripts - that we improve.

If English has been a familiar face among our school subjects since middle school, statistics is a completely new territory. This doesn't only apply to us as researchers, but also first and foremost as an ordinary citizen as well: there is a notable lack of appreciation for quantitative evidence and understanding of very basic statistical concepts in the Vietnamese public, which persists even in political and social debates that should have required empirical backups such as the questions of national health insurance or fiscal policies. Under the supervision of our mentor, we have come to understand the importance of data and statistical analysis. Once again, we learn and practice everything from working directly on real data and manuscripts intended for publication. Starting with cleaning the data and performing simple descriptive data analysis, then, we learn by re-running the model and compare the results with my mentor's. Day by day, manuscript by manuscript, we gradually master these skills. Once in a while, there would be a moment of what seemed like a collective defeat; we would tell each other that we had no clue what we were doing, only for Tung to explain to me the very next day the exact syntax mistake he'd spotted in our R commands, for example.

The experience gradually changes, there are moments when you will be satisfied with your work, and then there are moments when everything you've written just feels like rubbish. But that is how we know what improvement feels like. It feels like less of a ladder than the Penrose stairs. You climb up just to find out that you climb down as well, and at some point, you feel like you have ended up right where you started. But just as in the Penrose stairs, such feelings are illusions. Improvement is not linear because you have to constantly learn and unlearn, evaluate and re-evaluate, and deconstruct to create a better version. That is science as well. I think the best anyone could do is to find the confidence, trust your teammates' judgments, and keep on fighting. 


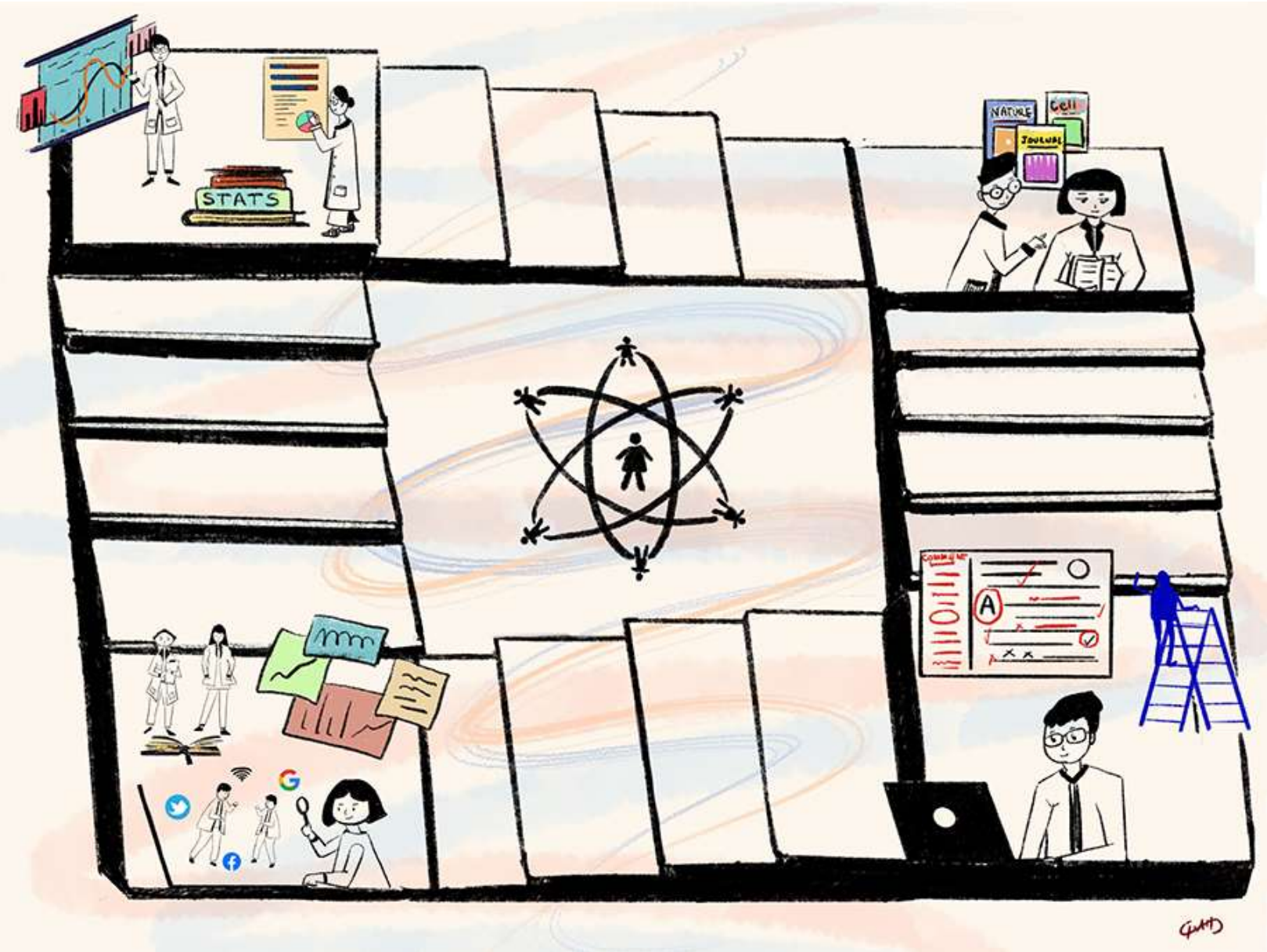

The Penrose stairs of science (@) drawing courtesy of Anh Hoang Ho)

\section{The not-so-straight path toward a PhD}

To Hong Kong, being able to have some publications does not mean that the path towards a Ph.D. and later a successful career is going to be straightforward: "Two years since the night I stayed up late to wrap up our first scholarly article, I am now a graduate student in Japan. The pressure to publish is always there, but for me, it is not so much this pressure that drives me toward this path, it is instead the pressure to be exposed to new ideas, to make mine known, and to have our research become influential beyond academia."

Not too long ago, I asked a senior academic on Twitter about when he was certain about his choice of career. He told me that it was around his second postdoc position, and he got his Ph.D. in his early 30s. I guess I still have time. The world of academia has welcomed us with its honest, sometimes soul-crushing, peer reviews, so we can find our soul-touching research [4]. It has taught us the importance of hearing criticisms and taking up criticisms well to become better. So, I can tell you this much: we will continue to walk on these Penrose stairs of science, because we love what we do. 

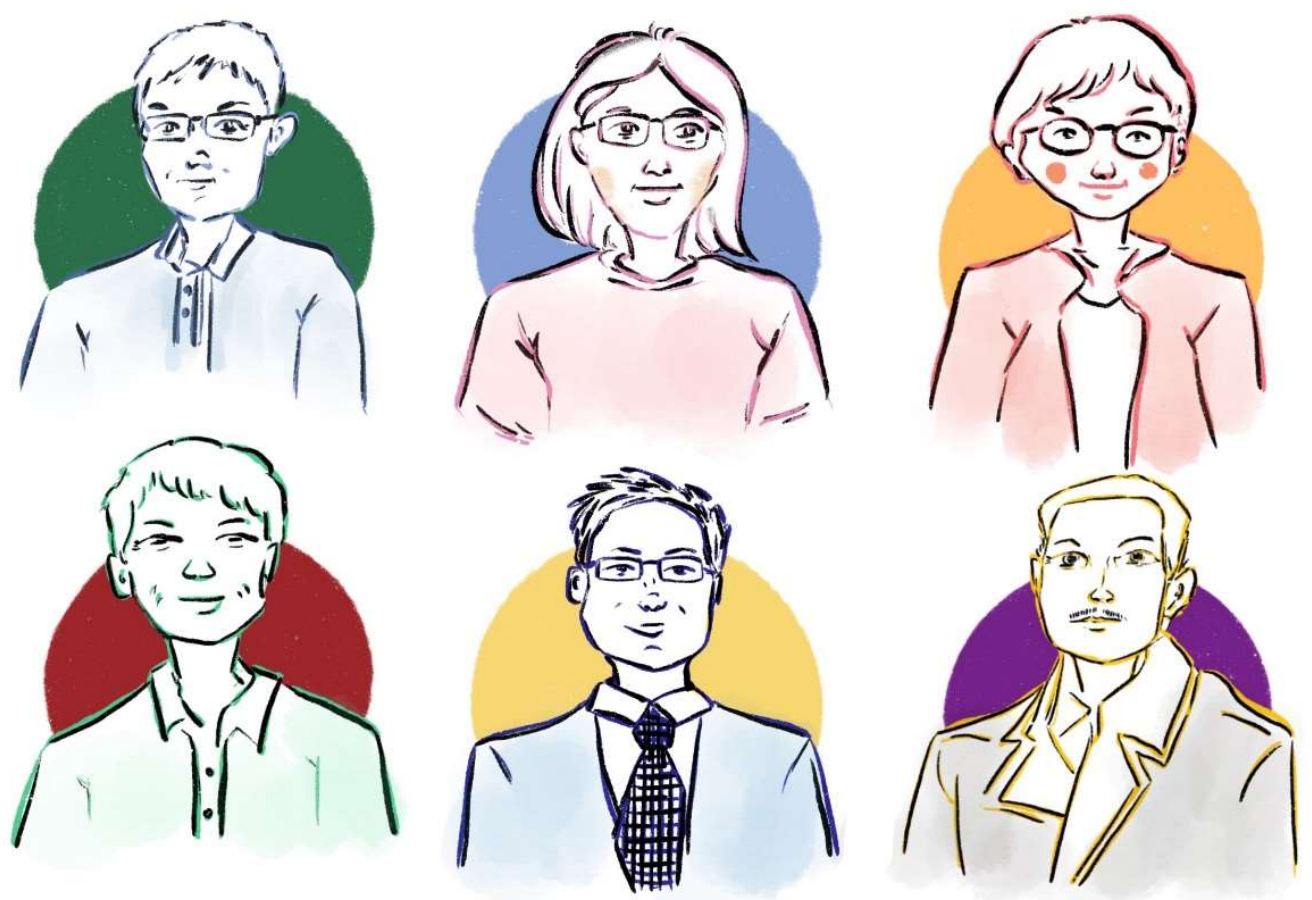

By the way, this is us (@ drawing courtesy of Anh Hoang Ho)

\section{References:}

[1] Vuong, Q. H., La, V. P., Vuong, T. T., Ho, M. T., Nguyen, T. H. K., Nguyen, T. V. H., Pham, H. H., \& Ho, M. T. (2018). An open database of productivity in Vietnam's social sciences and humanities for public use. Scientific Data, 5, 180188, DOI: 10.1038/sdata.2018.188.

[2] Ho, T. M., Nguyen, H. K. T., Vuong, T. T., \& Vuong, Q. H. (2017). On the sustainability of coauthoring behaviors in Vietnamese social sciences: A preliminary analysis of network data. Sustainability, 9(11), 2142, DOI:10.3390/su9112142.

[3] Vuong, Q. H., La, V. P., Vuong, T. T., Nguyen, V. H., Ho, M. T., Nguyen, T. H. K., Bui, Q. K., \& Ho, M. T. (2018). Cultural additivity: Behavioural insights from the interaction of Confucianism, Buddhism, and Taoism in folktales. Palgrave Communications, 4, 143. DOI:10.1057/s41599-018-0189-2.

[4] Vuong, Q. (2019, September 20). The quest for soul-touching research in the social sciences and humanities. OSF Preprints. DOI: 10.31219/osf.io/uht2w 